\title{
HIGH-ENERGY LIQUID JET TECHNOLOGY - RISK ASSESSMENT IN PRACTICE
}

\author{
IRENA M. HLAVÁČCVÁ ${ }^{1}$ and IWONA MULICKA ${ }^{2}$ \\ ${ }^{1}$ VŠB - Technical University of Ostrava, Ostrava, Czech Republic \\ Institute of Physics, Faculty of Mining and Geology \\ ${ }^{2}$ Opole University of Technology, Opole, Poland \\ Faculty of Production Engineering and Logistics
}

\begin{abstract}
Objectives: The contribution deals with a risk assessment in practical applications of the high-energy liquid jet technology from the point of view of the risk identification, estimation and evaluation. Materials and Methods: Differences between three different types of workplaces are highlighted and analysed - the indoor, the outdoor and the research ones. Theoretical analyses are supported by particular application of the method for the risk assessment in the Laboratory of Liquid Jets at the VŠB - Technical University of Ostrava. This laboratory is primarily oriented to research. Nevertheless, the conclusions can be used also for predominantly commercial workplaces. Results: Some new considerations and evaluations concerning health and safety are presented. Conclusions: Failure Mode and Effect Analysis (FMEA) procedures were applied and their limitations in risk assessment of water jet-based technologies are explained.
\end{abstract}

Key words:

High-energy liquid jet technology, Risk assessment, Sources of risks, Health and safety, FMEA analysis

\section{INTRODUCTION}

\section{High-Energy Liquid Jet Benefits and Hazards}

High-energy liquid jet represents a prospective tool in many spheres of human activity like coal mining [1], engineering, car and aircraft industry [2] or demilitarisation activities [3]. This technology has become very popular also in machining, where it replaces or complements conventional cutting, drilling or milling [4].

The main proclaimed benefits of the technology are:

- cold machining without thermal stress,

- cutting in any material and 2D or even 3D shape,

- high cutting accuracy,

- low environment burden,
- high thickness limit (up to $300 \mathrm{~mm}$ ),

- low requirements on fixing,

- narrow kerfs saving material.

Softer materials like rubber and foam are cut by pure water jet, abrasive water jets cut harder materials like steel, titanium, hard rock, common or bullet-proof glass, ceramics and even such materials as corundum or carbides. The continuous improvement of the technology includes deeper study of relationships between material properties and cutting quality $[5,6]$ aimed at better understanding of the cutting process as well as prediction and analyses of its results. The basis for theoretical description of the interaction between the jet and material was derived in the

Received: January 23, 2012. Accepted: April 26, 2012.

Address reprint request to I.M. Hlaváčová, Institute of Physics, Faculty of Mining and Geology, VŠB-Technical University of Ostrava, 17. Listopadu 15/2172, 70833 Ostrava, Czech Republic (e-mail: irena.hlavacova@vsb.cz). 
nineties of the twentieth century and later supported by abrasive particle research [7].

In further improvement of the production quality the risk assessment based on the FMEA should be helpful similarly to other industrial processes analysed by this method $[8,9]$. The concurrent application of this method for simultaneous evaluation of the process effectiveness and health and safety risks to the operators, however, can yield some misrepresenting results. This assumption will be discussed in the paper.

The technology has become fairly frequent because it is advertised to be "friendly and easy to use". Therefore, it should be well estimated especially from the point of view of reliability and safety. Although in the international scale a great attention is paid to these problems, competent papers dealing with this problem are still very rare in Eastern Europe.

Generally, it can be said that three basic types of workplaces can be distinguished. The commercial indoor and outdoor ones are the basic types. The third one is a research workplace that has several specific features. The basic common characteristic of all indoor workplaces is the highly pressurized water (100-700 MPa) passing through a small orifice $(0.1-0.5 \mathrm{~mm})$ concentrating the high energy into a tiny area to cut or blast material. The velocity of the issuing water thus may reach values up to $1100 \mathrm{~m} \times \mathrm{s}^{-1}$. Enormous energy concentrated on the area smaller than one tenth of square millimetre brings along the fact that the technology may be really dangerous for a human being if improperly used. Although only medium-pressure $(\sim 30 \mathrm{MPa})$ water may be used either in the pulsing jet form [10] or with abrasives [11], in many outdoor applications the concentration of energy still exceeds reasonable limits for a human body [12]. Therefore, the working conditions for outdoor workers, frequently operating handheld devices, may be really dangerous.

The abrasive water jets (AWJ), in fact consisting of two or three components (the mixture of water and solid particles or water, solid particles and air), are produced either as slurry jets or injection jets. Slurry jet velocities resulting from the identical pressure are about 20-30\% higher and, therefore, more dangerous.

The producers have always paid much attention to the high reliability of individual components of the system both in selection of material and construction design, being aware that risks connected with highly pressurized water could be enormous. Therefore, most of the severe failures connected with the technology can be ascribed to the human factor, either inattention or carelessness.

\section{Sources of the water jet risks and the ways of protection}

The brief description of the physical background of the technology should make it clear that the most important and dangerous is the jet emerging from the nozzle. This risk can be eliminated or reduced either by directing the stream solely to the regions where no harm is supposed (catcher basin), or by the use of various protective measures (clothes, tools with two triggers which both have to work before the lance becomes active, some protective shutter etc.) or marking out the dangerous and safe sectors.

Other parts of the high-pressure circuit also represent important sources of danger. Fittings can fail and couplings can come apart. Although pressure of the jet will drop almost immediately in such cases, even in the very short period of time immediately after the failure the pressurized water in the hose may cause its flailing around and in that way it may cause some damage or it can even hurt the operator. Fittings may also leak and cause the water to squirt at the same pressure as the jets coming from the nozzles at the end of the tool. Precautions to these failures are as follows: using proper fitting attached together in a proper manner, regular preventive inspection of all equipment, slow build-up of pressure to enable early detection of problems, and of course no repairs with the system under the pressure. All parts 
of the system with pressurized water should be enclosed in some protective covering.

Other risks connected with the technology result either from the type of application or they are somehow common to all machinery equipment. Among these the electric shock hazards should be mentioned (electrically fed equipment) as the first one, explosion hazards or oil leakage from the hydraulic system can be also quite dangerous. These failures are extremely rare in modern well-serviced machinery but their likelihood may dramatically rise if the proper planning, adequate training and equipment inspection are neglected.

\section{Characteristics and classification of the workplaces}

The most common and probably the safest applications of water jets include the in-door industrial applications with stationary high pressure water jet machines for cutting or turning, using both pure and abrasive water jets. Their operation is CNC controlled and the workplaces are very often semi- or fully automated. Protective optical or mechanical gates may be installed to prevent injuries due to an inadvertent contact of operator with the jet. However, very often it is necessary to manipulate with material quickly and preventing operator's access to the workplace may unreasonably slow down the process. Effective training programmes and safety measures intended to exclude persons intoxicated, taking medications, sick, tired or otherwise unwell from being allowed to operate the water jet cutting machines should perhaps bring the same or even better effect.

Sharp edges, either on a cut material or e.g. on the worn out catcher, may also represent a significant source of injuries, therefore protective gloves are recommended.

Water jet cutting is usually accompanied by a considerable noise burden potentially causing tinnitus, hearing impairment, or eventually deafness if prolonged exposures occur. It is supposed that most of the water jetting applications produce noise levels above $85 \mathrm{~dB}$ A-weighted. Therefore, ear protectors should be worn all the time the water jet is operating, especially when operating in a confined space. The application of silencers may be one of the precautions. Placing of the pump into a separate sound-conditioned room or using remote controlled water jet machines also reduces the operator's noise exposure.

Water or abrasive spattering may cause serious injury if the eyes are hit. The danger extends to the face skin if a brittle material, like glass, is being cut. Wearing of the protective glasses and the face shield is strongly recommended.

The above survey deals primarily with the industrial applications. Non-industrial applications mostly differ more or less; their characteristics rather resemble those of the outdoor ones. The severity of the risk may change to great extent in individual workplaces. Examples of the possible failures are: internal injury (medicine), bruising from the fallen work-piece (rock mining), falls (blasting of high buildings), hitting of person standing at the side (internal blasting of vessels), displacement of the nozzle and subsequent injury to the legs and feet (submerged non-automated applications), demolition (fire-fighting). Also the noise is a serious problem, because its levels exceed the values specified for the in-door applications if the jet blows over a long distance in the open air [13].

Research workplaces usually abide by common safety regulations because skilled and competent workers employed there are less likely to act recklessly. In this paper, some key problems concerning the technology are analysed from the point of view of the Laboratory of Liquid Jet (LLJ) at the VŠB - Technical University (VŠB-TU) of Ostrava. The risk assessment based on the FMEA(Failure Mode and Effect Analysis) method was performed and it is reviewed here and modified. Subsequently, some general experience is discussed and knowledge from the outdoor applications is compared with the evaluation of risks inherent for the in-door workplace. 

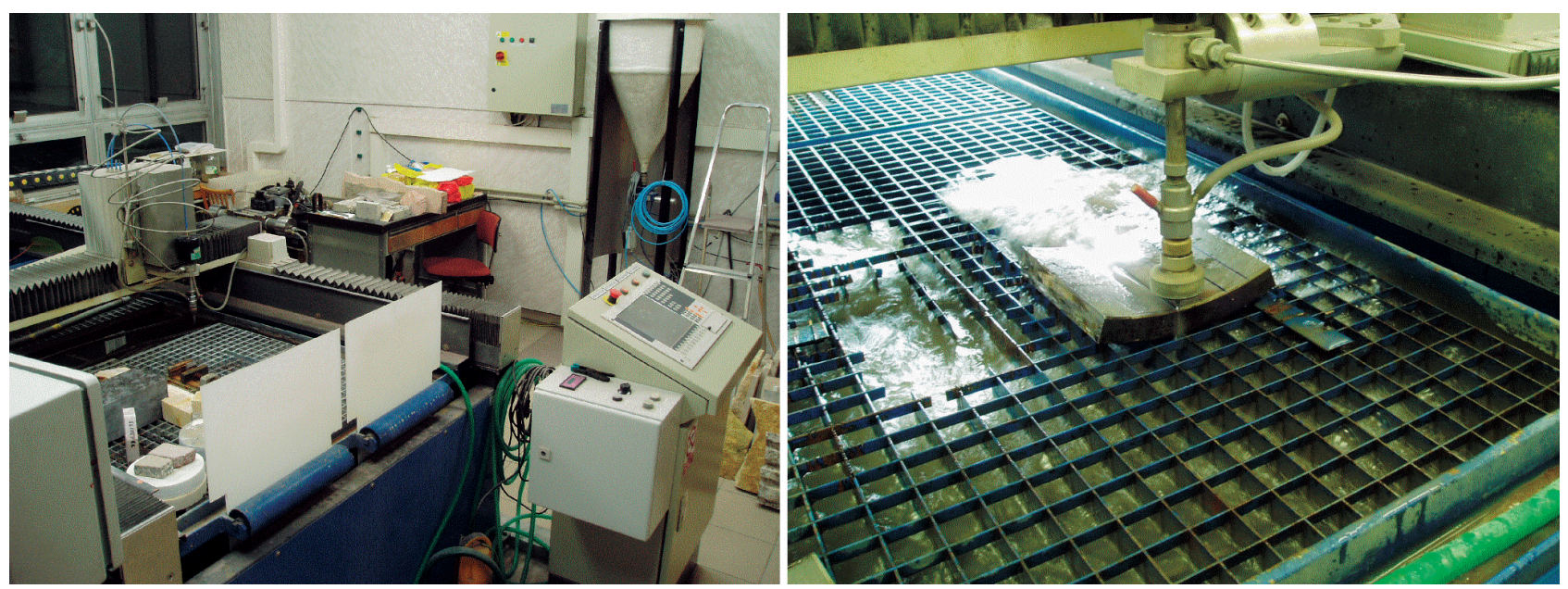

Photo 1. Laboratory of the Liquid Jets at the VŠB - Technical University of Ostrava

\section{The Laboratory of Liquid Jet at the VŠB -}

\section{Technical University of Ostrava}

The high-energy liquid jet technology has been studied at the VŠB - Technical University of Ostrava since 1997. The Laboratory of Liquid Jet (LLJ) at the Institute of Physics was established and equipped with the pump capable of producing pressure adjustable from 55 to $395 \mathrm{MPa}$ at the flow rate up to 1.9 litres per minute. The CNC controlled $x-y$ table $2 \times 1 \mathrm{~m}^{2}$ (with a manually driven $z$-axis and manually set tilting $\pm 90^{\circ}$ in the $x$ - $z$ plane) has been installed in 2005. Material processing is semi-automated.

The CNC controlled cutting process is combined with manual material handling system (Photo 1).

During 7 years of operation, many kinds of materials were cut, various techniques were used and the whole process was thoroughly studied. No injuries have occurred during the whole life of the laboratory and no serious health problems have been reported. The ear and eye protection has been uncompromisingly used during the cutting process.

Some failures have occurred: the work-piece falling into the catcher (the most often), water and abrasive scattering (from the water basin slats) damaging certain materials like glass (Photo 2), congestion of the abrasive feeding hose or tube, insufficient air pressure for abrasive feeding control, improper adjustment of the water nozzle and the focussing tube, sudden water pressure drop due to pump failure (Photo 3), water nozzle damage, CNC control unit failure, one broken high-pressure capillary tube (far enough from the operator) combined with perforation of the protective metal shrouding (Photo 4).

Up to now no evaluation of air or water pollution has been attempted. Acoustic measurements were carried out in the laboratory several times and evaluated from different points as part of bachelor or master theses. Noise arising both from the pump operation and the cutting itself results in the decibel level amounting to hygienic limits for the low frequencies (below $8 \mathrm{kHz}$ ) and even exceeding

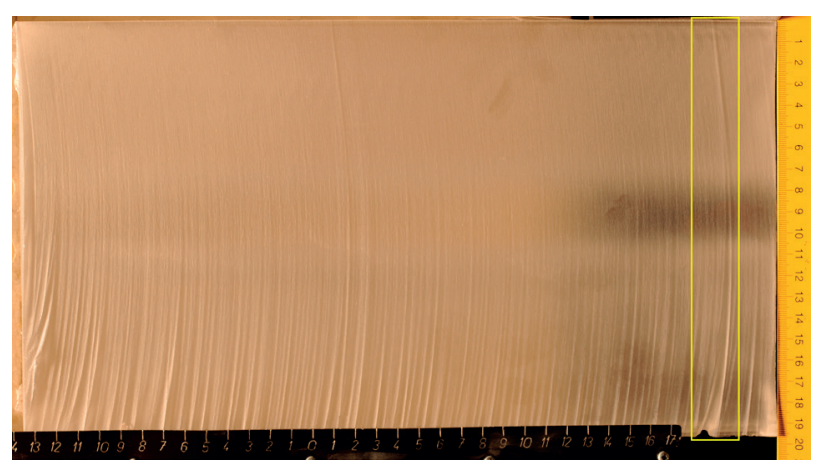

Photo 2. Experimental cutting of glass in the LLJ - scattering of the jet on the slat 


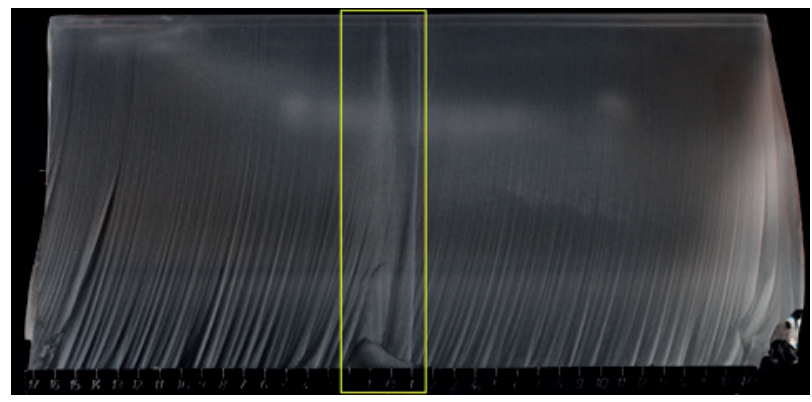

Photo 3. Damage of the glass due to the sudden pump shutdown near the slat

them (by as much as $10 \mathrm{~dB}$ ) for the high frequencies (according to the Czech Standard). The limit for ultrasonic frequencies may be exceeded as well (by up to $19 \mathrm{~dB}$ ) if the improper location of the work-piece is used, i.e. the jet passes a long distance in the air [14].

\section{MATERIALS AND METHODS}

\section{Use of risk assessment method}

The Failure Mode and Effect Analysis (FMEA) is a qualitative analysis of hazard identification universally applicable in a wide variety of industries [15]. Its weak point is that it does not take into consideration the consequences of the human factor (human errors and failures). It is possible, however, to use the method for identification of the components most responsive to the human failures and suggest the effective measures eliminating primarily those adverse influences.

The basic idea of FMEA is to spot risks and to initiate dedicated efforts to control or minimize risks. Supposing

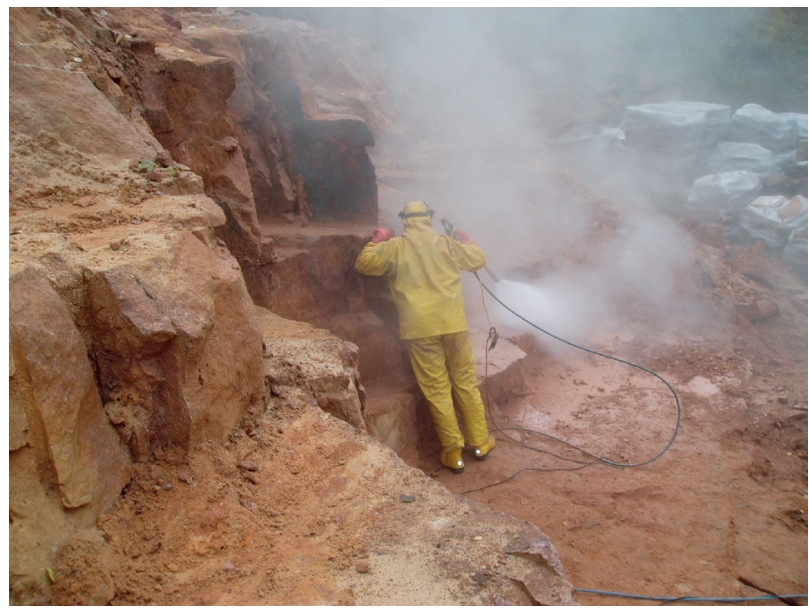

Photo 5. Water jet testing in sandstone quarry Javorka (Czech Republic)

that the analysis should be evaluated numerically it is useful to include the criticality analysis and replace FMEA by FMECA. Two different approaches should be used: mapping the criticality matrix or the risk priority number evaluation. The second approach seems to be more useful in the case of water jet technology. Analysing the technology, it is necessary to divide the system into the key subsystems and to identify the failure modes of these subsystems. For each system individual risk assessment is carried out based on identification of severity, occurrence and detectability.

The subsystems of the workplace with water jet should be like presented in Figure 1:

- water supplying system,

- abrasive feeding system,

- material supply and manipulation,
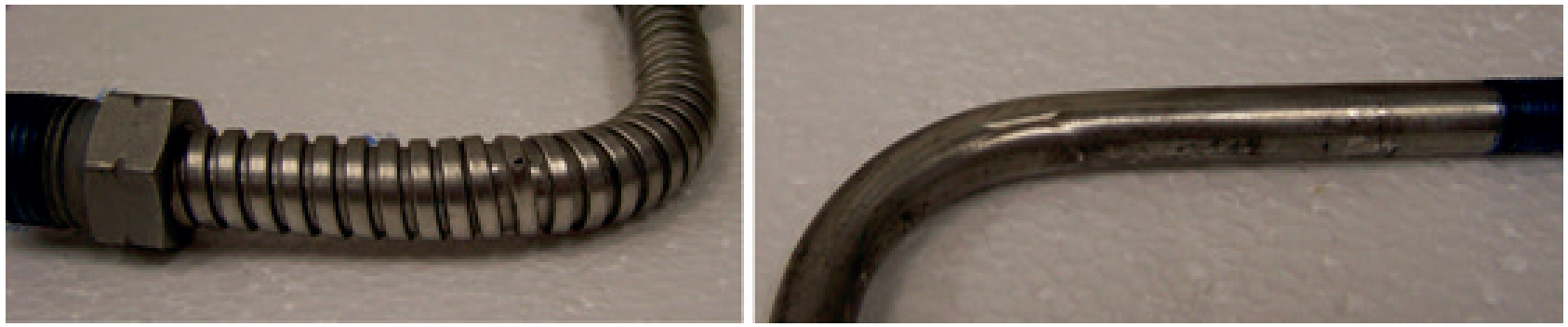

Photo 4. Damaged shrouding of the broken high-pressure capillary 


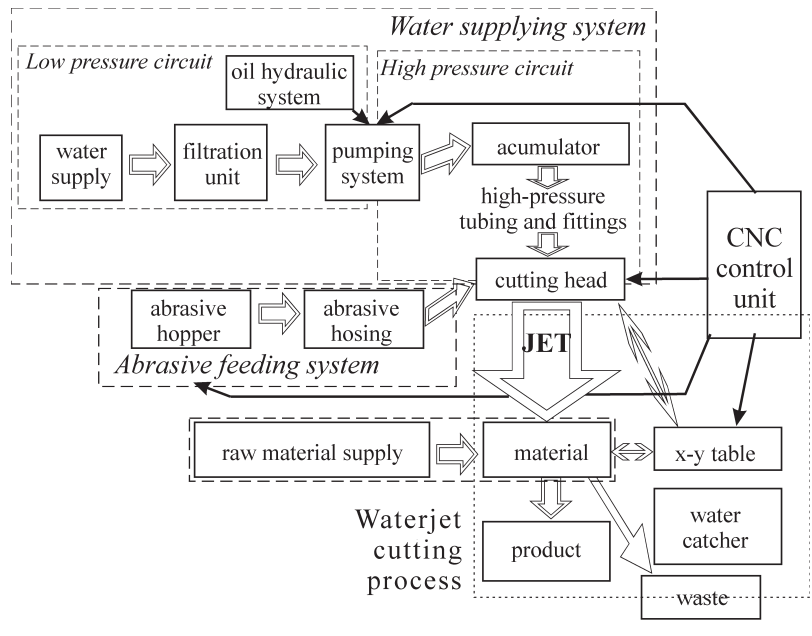

Fig. 1. Main subsystems of water jet cutting

- control CNC system,

- final work-piece and waste.

\section{Severity}

Severity (S) expresses the consequences of a failure mode. Severity considers the worst potential consequence of a failure, determined by the degree of injury, property damage, or system damage that could ultimately occur. In proposed sample evaluation a ten-point scale was used. The failures were assessed from the point of view of the product quality and proper operation of the equipment.

\section{Occurrence (probability)}

It is necessary to look at the cause of a failure and how many times it occurs. This can be done following the documents about failures in similar processes. A failure cause is looked upon as a design weakness. All the potential causes for a failure mode should be identified and documented. This brief paper, however, includes only some very often or the most serious examples of causes: water nozzle damage, air pressure drop down, improper operating conditions or person injury. A failure mode is given a probability number $\mathrm{O}$, a ten-point scale was used as in the case of severity. Actions need to be determined if the occurrence is high (i.e. it exceeds 4 for non-severe failure modes or it exceeds 1 in cases when the severity number is 9 or 10 ).

\section{Detectability}

Detectability (D) refers to an ability to identify failures of the system correctly by design control regardless of how dramatic or subtle they may be. Absolute uncertainty should be classified 10, almost certain detection 1 .

\section{Risk Priority Number}

Having ranked the severity, occurrence and detection modes, the Risk Priority Number (RPN) is calculated by multiplying the three numbers. By comparing the RPN numbers, the areas of the greatest concern are identified and given the highest priority for corrective action. Although the theoretical instruction seems to be legitimate and clear, following it exactly may be misleading or false in the case of water jet technology [16]. A single evaluation for two quite different events: quality of the product and operation of the system on the one side and health and safety of the operating staff on the other side is counter-productive. Fatal consequences for the operator of some failures may be accompanied by perfect product. Insufficient quality of water on the other hand makes no harm to the personnel and at the same time may destroy the nozzle and stop the operation. Therefore, the risks and hazards should be evaluated twice, firstly from the point of view of the consequences to work-piece quality and secondly with reference to the consequences to human health (Table 1).

It is obvious that this procedure cannot fully determine all really hazardous exposures or events. Although noise is one of the most hazardous exposures of the technology [13], it has got the RPN only 90, because its detectability is evaluated from the point of view of the equipment - it is certain that the noise should be detected. Detection of the impairment of the operator hearing should give quite different result and such change in evaluation 
Table 1. Double evaluation of the Risk Priority Number (RPN) carried out separately for material damage only (MD) and health and safety risks (HS) according to the experience in the Laboratory of Liquid Jet

\begin{tabular}{|c|c|c|c|c|c|c|}
\hline \multirow{2}{*}{ Failure mode } & \multicolumn{2}{|c|}{$\mathrm{S}$} & \multirow{2}{*}{$\mathrm{O}$} & \multirow{2}{*}{$\mathrm{D}$} & \multicolumn{2}{|c|}{ RPN } \\
\hline & MD & HS & & & $\mathrm{MD}$ & HS \\
\hline Insufficient quality of water & 3 & & 5 & 3 & 45 & \\
\hline Oil leakage & & 3 & 1 & 3 & & 9 \\
\hline Oil spattering & & 8 & 1 & 10 & & 80 \\
\hline Greasy floor & & 6 & 3 & 1 & & 18 \\
\hline High pressure water fitting leakage & 6 & & 2 & 5 & & 60 \\
\hline High pressurized water spattering & & 9 & 1 & 10 & & 90 \\
\hline Sudden high-pressure drop down & 9 & & 2 & 9 & 162 & \\
\hline Water nozzle damage & 9 & & 3 & 4 & 108 & \\
\hline Abrasive feeding system failure & 9 & & 5 & 2 & 90 & \\
\hline Focusing tube clogging or damage & 7 & & 3 & 4 & & 84 \\
\hline Pressurized air drop-off & 5 & & 4 & 1 & 20 & \\
\hline Direct hit by AWJ & & 10 & 1 & 8 & & 80 \\
\hline Sudden rebounding of abrasive particle or material piece & & 5 & 8 & 4 & & 160 \\
\hline Weak material fixing & 9 & 5 & 4 & 4 & 144 & 80 \\
\hline Air pollution - inhalation of harmful or toxic materials & & 5 & 4 & 6 & & 120 \\
\hline Water pollution & & 2 & 6 & 7 & & 84 \\
\hline Work-piece fall into the catcher & 10 & & 9 & 1 & 90 & \\
\hline $\begin{array}{l}\text { Work-piece damage by the AWJ rebounded from the catcher } \\
\text { stiffeners and grid holders }\end{array}$ & 9 & & 4 & 2 & 72 & \\
\hline Sharp edges & & 3 & 10 & 5 & & 150 \\
\hline Electric shock hazard & & 8 & 1 & 6 & & 48 \\
\hline Noise & & 9 & 10 & 1 & & 90 \\
\hline Discomfort from wearing of protectors and noise exposure & & 10 & 7 & 2 & & 140 \\
\hline
\end{tabular}

AWJ - abrasive water jet, $\mathrm{S}$ - severity, $\mathrm{O}$ - ocurrence, D - detectability.

parameter may substantially improve the quality of the analysis. This conclusion can be generalized, especially for the failure modes concerning health and safety in a following way: The value of detectability of a failure mode, particularly that one which has got a wide range of possible health harm consequences, should be determined regardless of the severity and occurrence number. It means the maximum value referring to any possible consequence, not only the worst or the most frequent one. After having applied this approach, the value of noise detectability should rise at least to 4-5, giving the final RPN 360. This adjustment of the evaluation was included in the following risk assessment of practical application of water jetting in the sandstone quarry Javorka, Czech Republic (Photo 5) representing an outdoor workplace with a hand-handled pure water jet.

\section{RESULTS}

The results of the analysis are summarized in Table 2. 
Table 2. Evaluation of the Risk Priority Number (RPN) for material damage only (MD) and health and safety risks (HS) based on the experience in the quarry Javorka

\begin{tabular}{|c|c|c|c|c|c|c|}
\hline \multirow{2}{*}{ Failure mode } & \multicolumn{2}{|c|}{$\mathrm{S}$} & \multirow{2}{*}{$\mathrm{O}$} & \multirow{2}{*}{$\mathrm{D}$} & \multicolumn{2}{|c|}{$\mathrm{RPN}$} \\
\hline & $\mathrm{MD}$ & HS & & & $\mathrm{MD}$ & $\mathrm{HS}$ \\
\hline Insufficient water supply & 9 & & 5 & 3 & 135 & \\
\hline Insufficient fuel supply & 9 & & 5 & 3 & 135 & \\
\hline Oil leakage & & 3 & 1 & 3 & & 9 \\
\hline Oil spattering & & 6 & 1 & 9 & & 54 \\
\hline Greasy ground & & 6 & 3 & 1 & & 18 \\
\hline High pressure water fitting leakage & 6 & & 2 & 5 & & 60 \\
\hline High pressurized water spattering & & 9 & 2 & 10 & & 180 \\
\hline Sudden high-pressure drop down & 1 & 8 & 2 & 7 & 14 & 112 \\
\hline Water nozzle damage & 3 & & 3 & 4 & 36 & \\
\hline Direct hit by water jet & & 10 & 2 & 8 & & 160 \\
\hline Air pollution & & 5 & 4 & 6 & & 120 \\
\hline Water pollution & & 2 & 6 & 7 & & 84 \\
\hline Sharp edges & & 3 & 10 & 5 & & 150 \\
\hline Electric shock hazard & & 4 & 1 & 6 & & 24 \\
\hline Fire & & 5 & 1 & 1 & & 5 \\
\hline Noise (impairment of the operator hearing) & & 9 & 10 & 4 & & 360 \\
\hline Discomfort from wearing of protectors and noise exposure & & 10 & 7 & 2 & & 140 \\
\hline
\end{tabular}

Abbreviations as in Table 1.

\section{DISCUSSION}

There are surely various viewing angles that may influence the results of risk analysis [14]. The presented one is aimed at the basic problems of jetting technologies as known from several observed practical applications. One of the main intentions is to point out the weak deductions based on the results of the FMEA or FMECA methods. It is obvious that failure modes mostly lead either to the failure of the equipment or to the impairment of the crew. There are only very few failures which may be dangerous to some extent from the both points of view. These are "weak material fixing" in the case of an indoor stationary workplace - the work-piece may be wrong cut or it may cause an injury of staff and "sudden high-pressure drop down" in the case of an outdoor man-operated flexible workplace - the cutting or blasting may be wrong done or the operator may lose stability and fall down as a consequence of sudden unexpected disappearance of the backward force.

The results of the outdoor workplace analysis show that the importance of risks and hazards related to human body is much higher than those related to the work-piece. The main reason is that the required quality of the cutting results is much lower and so it is not so dependent on a sudden interruption unlike the case of the indoor precise abrasive water jetting. Therefore, it is necessary to pay much higher attention to the proper training of the staff working with water jets in outdoor applications than in the indoor ones.

The value of RPN in the second analysis may seem to be overestimated, but it must be taken into account that 
evaluation was done purposely for the case without application of the protective measures in order to emphasize the necessity of the ear protection.

\section{CONCLUSIONS}

Although there is a general feeling that accidents using high-energy water jets are relatively rare, the technology has become so widely used that risk assessment cannot be underestimated. Brief description of the results of the application of the FMECA method to the water jet cutting in the Laboratory of Liquid Jets at the VŠB - Technical University of Ostrava illustrated that the method should be modified, so that difference in ranking of failure modes from the point of view of the production quality and staff health and safety should not be suppressed. The simplest way to do this is to perform the assessment twice, separately from the both points of view. Final risk priority number should be weighted sum of the partial ones. There is no use in standardization of the value of the weighting factors; on the contrary, they represent a tool for individual characterization of the workplace, the importance of the solved tasks as well as skill and experience of the crew. In any case, determination of the weighting factors is rather executive than research task. Experienced water jet workers, however, are necessary for preparation of reliable ranking tables of severity, occurrence and detectability for both partial risk priority numbers. These are being prepared in the cooperation with several industrial and research work places. Including the risk assessment from environmental point of view is considered as well.

\section{REFERENCES}

1. Lu YY, Liu Y, Li XH, Kang Y. A new method of drilling long boreholes in low permeability coal by improving its permeability. Int J Coal Geol 2010; 84(2):94-102. DOI 10.1016/j. coal.2010.08.009.
2. Hashish M. A study on AWJ trimming of composite aircraft stringers. Proceedings of the ASME Pressure Vessels and Piping Conference. 26-30 July 2009; Prague, Czech Republic. Vol. 5. New York: American Society of Mechanical Engineers; 2010. p. 55-63.

3. Nambiath P, Galecki G, Tyler LJ, Fossey R, Summers DA. Parameter optimization in munitions cutting using abrasive waterjets. In: Hashish M, editor. Proceedings of the 2007 American WJTA Conference and Expo. 19-21 August 2007; Houston, Texas, USA. Houston: WJTA; 2007. p. 2-E.

4. Borkowski PJ. Application of abrasive-water jet technology for material sculpturing. T Can Soc Mech Eng 2010;34 (3-4):389-400.

5. Hlaváč LM. Investigation of the abrasive water jet trajectory curvature inside the kerf. J Mater Process Technol 2009;209(8):4154-61. DOI 10.1016/j.jmatprotec.2008.10.009.

6. Hlaváč LM, Hlaváčová IM, Gembalová L, Kaličinský J, Fabian S, Měštánek J, et al. Experimental method for the investigation of the abrasive water jet cutting quality. J Mater Process Technol 2009; 209(20):6190-5. DOI 10.1016/j.jmatprotec.2009.04.011.

7. Hlaváč LM, Martinec P. Almandine garnets as abrasive material in high-energy waterjet - physical modelling of interaction, experiment, and prediction. In: Louis $\mathrm{H}$, editor. Jetting Technology. Bury StEdmunds/London: Professional Engineering Publishing Ltd; 1998. p. 211-23.

8. Pitblado RM, Woodward JL. Highlights of LNG risk technology. J Loss Prev Process Ind 2011;24(6):827-36. DOI 827836; 10.1016/j.jp.2011.06.009.

9. Davis SG, Hinze PC, Hansen OR, Wingerden K van. Does your facility have a dust problem: Methods for evaluating dust explosion hazards. J Loss Prev Process Ind 2011;24(6):83746. DOI: 10.1016/j.jlp.2011.06.010.

10. Vijay MM, Yan W, Tieu A, Bai C, Pecman S. Removal of hard coatings from the interior of ships using pulsed waterjets: Results of field trials. In: Hashish M, editor. Proceedings of the 10th 
American Waterjet Conference. 14-17 August 1999; Houston, Texas, USA. Houston: WJTA; 1999. p. 677-94.

11. Husted BP, Holmstedt G, Hertzberg, T. The physics behind water mist systems. In: Proceedings of the IWMA Conference; 6-8 October 2004; Rome, Italy. Rome: IWMA; 2004. p. 1-15.

12. Axmann HD, Krause M, Laurinat A, Louis H, Meißner T. Damage mechanisms of injuries caused by high pressure water jets. Edmunds: Mechanical Engineering Publications; 1996. p. 309-17.

13. Hutt R. Noise from high pressure water jetting. Literature review. Buxton: Health \& Safety Laboratory; 2004 [cited 2010 October 28]. Available from URL: http://www.hse.gov.uk/ research/hsl_pdf/2004/hs10415.pdf.
14. Hlaváčová IM, Hlaváč LM, Mádr V, Janurová E, Uhlář R, Kaličinský J. Risk Assessment in Using the High-Energy Liquid Jet Technology. In: Gajek M, editor. Optimization of production processes. Opole: Opole University of Technology; 2008. p. 85-96.

15. Cameron I, Raman R. Process Systems Risk Management. Amsterdam, Netherlands: Academic Press, Elsevier; 2005. p. 615 .

16. WJTA. Recommended Practices For the Use of Manually Operated High Pressure Waterjetting Equipment. St. Louis: WaterJet Technology Association; 2003.

This work is available in Open Access model and licensed under a Creative Commons Attribution-NonCommercial 3.0 Poland License - http://creativecommons.org/ licenses/by-nc/3.0/pl/deed.en. 